Check for updates

Cite this: RSC Adv., 2017, 7, 49999

Received 18th August 2017

Accepted 21st October 2017

DOI: 10.1039/c7ra09150h

rsc.li/rsc-advances

\title{
Closed-loop solvometallurgical process for recovery of lead from iron-rich secondary lead smelter residues $\dagger$
}

\author{
Federica Forte, (D) ${ }^{a}$ Liesbeth Horckmans, ${ }^{\mathrm{b}}$ Kris Broos, ${ }^{\mathrm{b}}$ Eunyoung Kim, ${ }^{\mathrm{b}}$ \\ Frantisek Kukurugya ${ }^{b}$ and Koen Binnemans (D) *a
}

\begin{abstract}
A solvometallurgical process based on the use of concentrated acetic acid as lixiviant is proposed as an alternative for conventional hydrometallurgical processes to recover lead from iron-rich industrial residues generated by recycling of spent lead-acid batteries in a secondary lead smelter. Under the optimal conditions, a high selectivity for lead was obtained: more than $90 \%$ of the lead content could be dissolved, while only a small amount of iron $(<6 \%)$ was codissolved. Lead was quantitatively recovered from the acetic acid leachate by addition of a stoichiometric amount of sulphuric acid. Acetic acid was recycled by distillation and reused in the leaching step, so that a closed-loop process was obtained. The process was optimised for iron-rich residue (matte), but also a proof-of-principle is given for lead recovery from another lead-containing residue (slag). The main advantages of this solvometallurgical process are the low power consumption (room-temperature process), the low consumption of chemicals (only sulphuric acid is consumed), full recycling of the acetic acid and the limitation of waste water formation.
\end{abstract}

\section{Introduction}

Metal recovery from secondary sources has environmental and economic advantages because it allows delaying the depletion of primary ore deposits and requires much less energy than metal production from primary sources. Metallurgical slags produced by pyrometallurgical processes are potential secondary raw materials since they still contain considerable concentrations of metals. Ferrous slag, which includes iron slag, steel slag, alloy steel slag and ferroalloy slag is mainly treated through magnetic and gravity separation methods to recover chromium and nickel. ${ }^{1}$ Non-ferrous slag, which includes copper, zinc and lead slag, often has a high iron content, which is comparable to that of low-grade iron ores, and it can be used as a secondary iron source in a rotary kiln process. ${ }^{2}$ Metals other than iron can be recovered from nonferrous slag. An extensive body of literature is available on the recovery of copper, zinc and cobalt from copper slag, which is usually treated by flotation, ${ }^{3}$ roasting ${ }^{4}$ and leaching. ${ }^{5}$

Each year 200000 tonnes of lead slag are being produced by recycling of lead by secondary lead smelters, as well as 280000 tonnes of sludge by neutralisation of the sulphuric acid

${ }^{a} K U$ Leuven, Department of Chemistry, Celestijnenlaan 200F, bus 2404, B-3001 Heverlee, Belgium. E-mail: Koen.Binnemans@kuleuven.be

${ }^{b}$ VITO NV, Boeretang 200, B-2400 Mol, Belgium

$\uparrow$ Electronic supplementary information (ESI) available: X-ray diffraction patterns of matte and slag. See DOI: 10.1039/c7ra09150h contained in lead-acid batteries. ${ }^{6}$ The particle size distribution of lead slag is very heterogeneous and there is a great variability in its chemical composition, which is strongly affected by the efficiency of the employed pyrometallurgical process. ${ }^{7}$ Some literature studies focus on the reuse of lead slag in construction materials, ${ }^{\mathbf{8}, 9}$ but only few studies have considered the recovery of metals from lead slag. Smaniotto et al. investigated the recovery of lead from lead slag of a battery recycling plant by using the chelating agent EDTA as a lixiviant (=leaching agent). ${ }^{7}$ However, EDTA is quite expensive and difficult to remove from aqueous waste streams. Shirinbayan et al. studied the kinetics of leaching lead from smelting furnace slag with hydrochloric acid. ${ }^{10}$ Ferracin et al. investigated the recovery of lead from sludges of exhausted lead-acid batteries by leaching with $\mathrm{HBF}_{4}$ followed by electrowinning of the dissolved lead. ${ }^{11}$ Major disadvantages of hydrometallurgical leaching processes are the generation of large volumes of waste water and the often limited selectivity, particularly if strong inorganic acids $\left(\mathrm{H}_{2} \mathrm{SO}_{4}, \mathrm{HCl}\right.$, $\mathrm{HNO}_{3}$ ) are used as leaching agent.

In the work of Kim et al. selective leaching of lead and other minor elements from secondary lead smelting residues was observed with several nitric acid-based systems. ${ }^{12}$ The authors found that in the presence of $0.15 \mathrm{M} \mathrm{Fe}(\mathrm{III})$ as oxidising agent, $90 \%$ of the lead was leaching, whereas iron codissolution was less than $25 \%$. Selective leaching of copper, nickel and zinc was achieved by roasting at $600{ }^{\circ} \mathrm{C}$ followed by water leaching and pressurised leaching in $0.5 \mathrm{M} \mathrm{HNO}_{3}$. A selective leaching of lead, copper, nickel and zinc from the same residue was also 
observed by citrate leaching. ${ }^{13}$ Lead leaching in $1 \mathrm{M}$ sodium citrate solution was highest (93\%) in the presence of $0.5 \mathrm{M}$ $\mathrm{H}_{2} \mathrm{O}_{2}$. In these conditions, iron was almost not leached $(<0.6 \%)$. An oxidative roasting step prior to leaching improved the leachability of the target metals, with maximum leaching efficiency reached at $600{ }^{\circ} \mathrm{C}$ for lead (93\%), copper (80\%) and zinc $(60 \%)$ and at $650{ }^{\circ} \mathrm{C}$ for nickel (53\%).

To overcome the issue of lack of selectivity of inorganic chemistry, organic acids can be used as a lixiviant. For instance, acetic acid is known for its capability to dissolve lead compounds. ${ }^{\mathbf{1 4}}$ Leaching of lead from galena $(\mathrm{PbS})$ in acetic acid solutions with hydrogen peroxide as oxidizing agent was studied by Aydoğan et $a l .{ }^{15}$ Nagib and Inoue investigated the recovery of lead and zinc from municipal solid waste incineration fly ash by leaching with several leaching agents, including acetic acid. ${ }^{\mathbf{1 6}}$ Barrett et al. described a process based on a $3 \mathrm{M}$ acetic acid solution to remove zinc, lead, copper and cadmium from carbon steel electric arc furnace dust. ${ }^{17}$ However, all these processes are still hydrometallurgical processes and generate aqueous waste streams. The formation of aqueous waste streams can be avoided by replacing water with an organic solvent and by working in a closed-loop process in which the organic solvent is recycled. Processes based on the use of solvents other than water are called "solvometallurgical processes". ${ }^{18}$ Solvometallurgical processes can have a high selectivity. For instance, it was shown that the red phosphor $\mathrm{Y}_{2} \mathrm{O}_{3}: \mathrm{Eu}^{3+}$ could selectively be dissolved from a complex fluorescent lamp phosphor waste by using a carboxyl-functionalised ionic liquid. ${ }^{19}$ Abbott and coworkers demonstrated that sulfides and similar minerals could be oxidatively dissolved in deep-eutectic solvents based on choline chloride and ethylene glycol. ${ }^{\mathbf{2 0 , 2 1}}$

In this paper, we describe a process to recover lead from residues from a secondary lead smelter, in which concentrated acetic acid is used as leaching agent to largely reduce the generation of waste water. A small amount of sulphuric acid is added in the separation step to precipitate lead as lead sulphate from the leachate. Acetic acid can easily be recycled through distillation and reused in the leaching step, thus ensuring a closed-loop process where only limited amounts of reagents are required. The recovered lead can be reused as a secondary raw material in a lead smelter, whereas the lead-depleted ironrich residue can find application as a secondary iron source or as a building material. According to the 2011 GSK's solvent selection guide and its updates, very few issues concerning human health or environmental hazards are related to the use of acetic acid as a solvent, so that this process can be considered as a green chemical process. ${ }^{22-24}$

\section{Experimental}

\section{Chemicals}

Acetic acid (100\%) was purchased from VWR Chemicals (Leuven, Belgium); $\mathrm{H}_{2} \mathrm{SO}_{4}$ (96\%) and Triton X-100 from Acros Organics (Geel, Belgium). Water was always of ultrapure quality, deionised to a resistivity of $18.2 \mathrm{M} \Omega \mathrm{cm}$ with a Sartorius Arium Pro ultrapure water system. The silicone solution in isopropanol was purchased from SERVA Electrophoresis $\mathrm{GmbH}$ (Heidelberg, Germany) and the standard solutions $\left(1000 \mu \mathrm{g} \mathrm{mL} \mathrm{L}^{-1} \mathrm{Ga}\right.$, Dy and
La) from Merck (Overijse, Belgium). All chemicals were used as received without any further purification.

\section{Analytical method}

Sample characterisation was performed by Wavelength Dispersive X-ray Fluorescence (WD-XRF, Axios PANalytical). Measurements were performed on powders, pressed into pellets. Mineralogical analyses were performed by X-ray diffraction (X'Pert PRO, PANalytical; Cu tube, fine focus, wavelength $\lambda\left(\mathrm{K}_{\alpha 1}\right)=$ $1.5406 \AA$, $2 \theta=2-120^{\circ}$, step size of $0.04^{\circ}$ ). The resulting diffractograms were analysed by the software HighScore Plus 4.0. The concentration of metals in solution was determined by Total Reflection X-ray Fluorescence spectroscopy (TXRF) with a Bruker S2 Picofox TXRF spectrometer equipped with a molybdenum source. ${ }^{25}$ Plastic microtubes were filled with a certain amount of the sample and diluted until $1 \mathrm{~mL}$ with ultrapure water/Triton solution $(5 \% \mathrm{w} / \mathrm{w}){ }^{26}$ An appropriate internal standard was added, with the X-ray fluorescence energy as close as possible to the element to be determined in order to reduce the effects caused by secondary X-rays absorption. After shaking the samples on a vibrating plate (IKA MS 3 basic), a small droplet $(5 \mu \mathrm{L})$ was put on a quartz carrier, previously treated with a silicone-isopropanol solution to avoid spreading of the droplet. The quartz carriers were then dried for $30 \mathrm{~min}$ at $60{ }^{\circ} \mathrm{C}$ prior to analysis. Each sample was measured for $500 \mathrm{~s}$. The composition of the solid residue obtained after leaching was determined by EDXRF (Energy Dispersive X-ray Fluorescence). The purity of the obtained lead sulphate was determined via Inductively Coupled Plasma Atomic Emission Spectroscopy (ICP-AES, Perkin Elmer, Optima $3000 \mathrm{DV}$ ). Prior to analysis the sample was processed by microwave digestion with $\mathrm{HCl}, \mathrm{HNO}_{3}$ and $\mathrm{HBF}_{4}$.

\section{Leaching tests}

The leaching tests were performed in glass vials located on a mechanical shaker (TMS-200 Turbo Thermoshaker). The solid samples were contacted with concentrated acetic acid and several operative parameters were varied in order to determine the optimal operative conditions, namely the contact time $(t=1-4 \mathrm{~h})$, the liquid-to-solid ratio ( $\mathrm{L} / \mathrm{S}=5 \mathrm{~mL} \mathrm{~g}^{-1}, 10 \mathrm{~mL} \mathrm{~g}^{-1}, 20 \mathrm{~mL} \mathrm{~g}^{-1}$ ) and the temperature $\left(T=25{ }^{\circ} \mathrm{C}, 50{ }^{\circ} \mathrm{C}, 75{ }^{\circ} \mathrm{C}\right)$. The agitation was kept constant at $2500 \mathrm{rpm}$ in all the experiments. The leachate was separated from the solid residue through centrifugation (5300 rpm, $30 \mathrm{~min}$ ) and analysed by TXRF to determine the leaching efficiency $E_{\mathrm{L}}(\%)$, which was calculated according to eqn (1):

$$
E_{\mathrm{L}}(\%)=\frac{m_{\mathrm{L}}}{m_{0}} \times 100
$$

where $m_{\mathrm{L}}$ is the mass of the dissolved metal (mg) and $m_{0}$ is the mass of metal in the initial sample (mg). Unless otherwise specified, each experiment was performed in duplicate.

Water-leaching tests with ultrapure water $(t=24 \mathrm{~h}, \mathrm{~L} / \mathrm{S}=$ $10 \mathrm{~mL} \mathrm{~g}^{-1}$ ) were performed on a leaching residue to verify the leachability of harmful elements and thus to assess a possible application of the residual solid matrix in for instance building materials. 


\section{Precipitation tests}

Recovery of lead from the leachate was investigated through precipitation with sulphuric acid $1 / 10 \mathrm{v} / \mathrm{v}$ in water, i.e. $1.8 \mathrm{M}$. Addition of sulphuric acid leads to the formation of insoluble $\mathrm{PbSO}_{4}$. Attention was paid to determine the optimal conditions (in terms of sulphuric acid consumption) to minimise coprecipitation of iron.

The solid residue was separated from the leachate through centrifugation (5300 rpm, $30 \mathrm{~min}$ ) and the supernatant was analysed to determine the precipitation efficiency $E_{\mathrm{P}}(\%)$, which was calculated according to eqn (2):

$$
E_{\mathrm{P}}(\%)=\frac{m_{\mathrm{P}}}{m_{\mathrm{L}}} \times 100=\frac{m_{\mathrm{L}}-m_{\mathrm{R}}}{m_{\mathrm{L}}} \times 100
$$

where $m_{\mathrm{P}}$ is the mass of metal precipitated (mg) and $m_{\mathrm{R}}$ is the remaining mass of metal in the leachate after precipitation (mg). Each experiment was performed in duplicate, as in the case of the leaching tests.

\section{Acetic acid recovery}

Recovery of acetic acid was investigated through distillation. The leachate obtained after a precipitation test with sulphuric acid was evaporated under reduced pressure at $T=50{ }^{\circ} \mathrm{C}$ by a rotary evaporator (Büchi R-210). The recovered solvent was used in a second leaching step to prove the feasibility of the proposed process.

\section{Results and discussion}

Samples were collected in a secondary lead smelter plant which treats spent lead-acid batteries and other lead-containing residues to recycle lead. At the bottom of the furnace three layers are formed based on density: (1) top: slag, mainly consisting of oxides; (2) middle: matte, mainly constituted by sulphides; (3) bottom: lead bullion, i.e. impure metallic lead, which is further refined. The slag and the matte are tapped into "slag pots". After cooling, the slag pots are turned over (Fig. 1) and the different layers are separated. The slag is broken and sieved; $2 / 3$ of the material (i.e. particles of a diameter of more than $15 \mathrm{~cm}$ ) is returned to the lead furnace, while $1 / 3$ of the slag, together with the matte, is disposed of.

Samples of slag and matte were pretreated through a milling step in order to obtain powders with particle size smaller than $125 \mu \mathrm{m}$. The chemical composition of the two materials was determined by WD-XRF analysis (Tables 1 and 2). The matte had a lead content of $8.2 \mathrm{wt} \%$ and the slag had a lead content of $4.0 \mathrm{wt} \%$. The iron content of the matte (51.4 wt\%) was considerably higher than that of the slag (36.6 wt\%). The XRD pattern (ESI, S1 $\dagger$ ) of the iron stone sample shows that iron is present mainly as sulphide (FeS, troilite) and oxide $\left(\mathrm{Fe}_{3} \mathrm{O}_{4}\right.$, magnetite; $\mathrm{FeO}$, wüstite). XRD analyses were also performed on the matte after magnetic separation; it was found that lead is present in the ferromagnetic fraction as metallic lead $(\mathrm{Pb})$ inside the FeS phase (ESI, S2 $\dagger$ ). In the slag, iron is present mainly as $\mathrm{Fe}_{2} \mathrm{SiO}_{4}$ (fayalite) and sulphide (FeS), whereas lead is present as sulphide (PbS, galena) and metallic lead (Pb) (ESI, S3 $\dagger$ ).

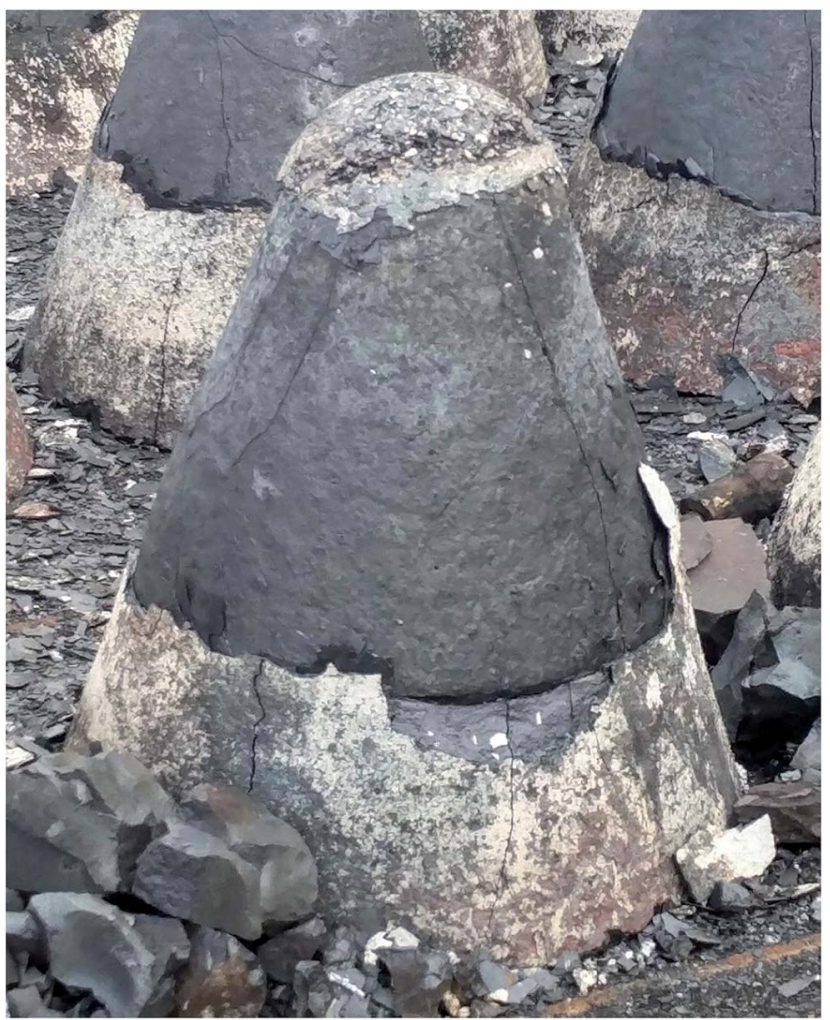

Fig. 1 Inverted slag pots, showing the slag at the bottom (light grey) and the matte (dark grey) at the top.

Table 1 Composition of the matte (wt\%)

\begin{tabular}{lllllllllll}
\hline $\mathrm{Fe}$ & $\mathrm{S}$ & $\mathrm{Pb}$ & $\mathrm{Cu}$ & $\mathrm{Ni}$ & $\mathrm{Si}$ & $\mathrm{Cl}$ & $\mathrm{Cr}$ & $\mathrm{Mn}$ & $\mathrm{Zn}$ & $\mathrm{Sn}$ \\
\hline 51.4 & 20.5 & 8.2 & 1.0 & 0.2 & 2.6 & 0.1 & 0.2 & 0.3 & 0.5 & 0.2 \\
\hline
\end{tabular}

The leaching process with acetic acid was optimised for the matte, because this residue is the most interesting one from an economical point of view: the matte has a high lead content and the iron content of the residue obtained after removal of lead is so high that this material can be used as a secondary raw material for iron production. Moreover, lead is present in the matte in the form of elemental lead (metallic lead) which is readily attacked by acetic acid in the presence of oxygen by producing very soluble lead(II)acetate. ${ }^{27}$ The process parameters for recovery of lead from the matte must be optimised in order to obtain maximum recovery of lead, while having minimum codissolution of iron.

In Fig. 2 the leaching kinetics of lead and iron from the matte sample are reported. The lead leaching kinetics with acetic acid are quite fast: only $2 \mathrm{~h}$ were required to dissolve more than $90 \%$ of the lead. By increasing the contact time up to $4 \mathrm{~h}$, the improvement in the dissolution efficiency for lead was negligible. The selected leaching agent shows a good selectivity of lead over iron. Iron is leached only to a small extent $(<6 \%)$.

The efficiency of lead leaching decreased as a function of temperature, whereas also more iron was dissolved at higher 
Table 2 Composition of the slag (wt\%)

\begin{tabular}{llllllllll}
\hline $\mathrm{Fe}$ & $\mathrm{S}$ & $\mathrm{Pb}$ & $\mathrm{Cu}$ & $\mathrm{Si}$ & $\mathrm{Cl}$ & $\mathrm{Cr}$ & $\mathrm{Mn}$ & $\mathrm{Zn}$ & $\mathrm{Sn}$ \\
\hline 36.6 & 6.5 & 4.0 & 0.4 & 7.6 & 0.1 & 0.4 & 0.5 & 0.5 & 0.2
\end{tabular}

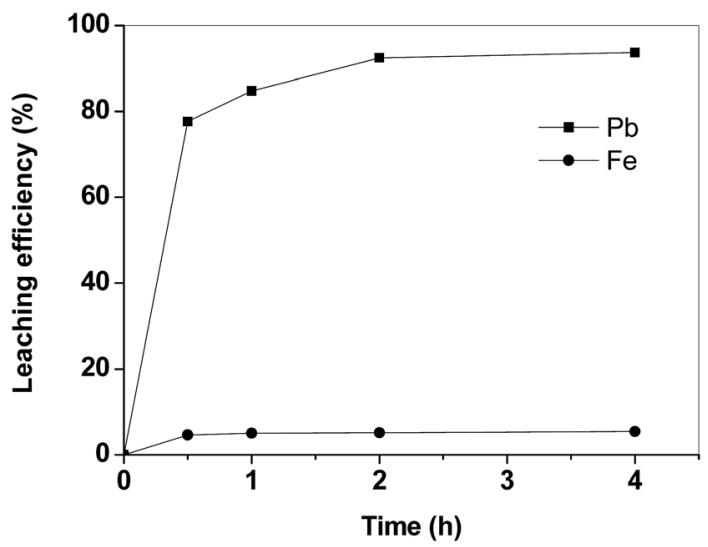

Fig. 2 Leaching kinetics for lead and iron from the matte $\left(T=25^{\circ} \mathrm{C}, \mathrm{L} /\right.$ $\mathrm{S}=10 \mathrm{~mL} \mathrm{~g}^{-1}$ ).

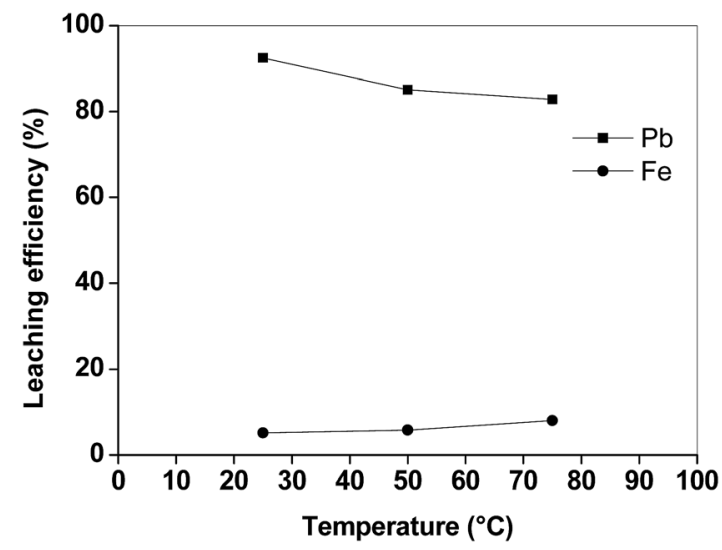

Fig. 3 Lead and iron leaching efficiency from the matte as a function of the temperature $\left(t=2 \mathrm{~h}, \mathrm{~L} / \mathrm{S}=10 \mathrm{~mL} \mathrm{~g}^{-1}\right)$.

temperatures (Fig. 3). This negative effect of the increasing temperature on the dissolution of lead is similar to what was found by Aydoğan et al. for longer contact times during the oxidative dissolution of galena $(\mathrm{PbS})$ in acetic acid/hydrogen peroxide mixtures. ${ }^{15}$ The authors suggested that the produced lead sulphate immediately precipitated at the surface of the unreacted galena, inhibiting further attack of hydrogen peroxide. Similar results were also obtained by Kim et al. ${ }^{13}$ who observed that lead and copper leaching with sodium citrate solutions decreased when the temperature increased from 25 to $70{ }^{\circ} \mathrm{C}$, whilst iron leaching efficiency increased. These results show that the leaching process with acetic acid is preferably performed at room temperature. By increasing the liquid-to-solid ratio $(\mathrm{L} / \mathrm{S})$ the leaching efficiency of lead increased (Fig. 4). In particular, by using a liquid-to-solid ratio of $20 \mathrm{~mL} \mathrm{~g}^{-1}$, about

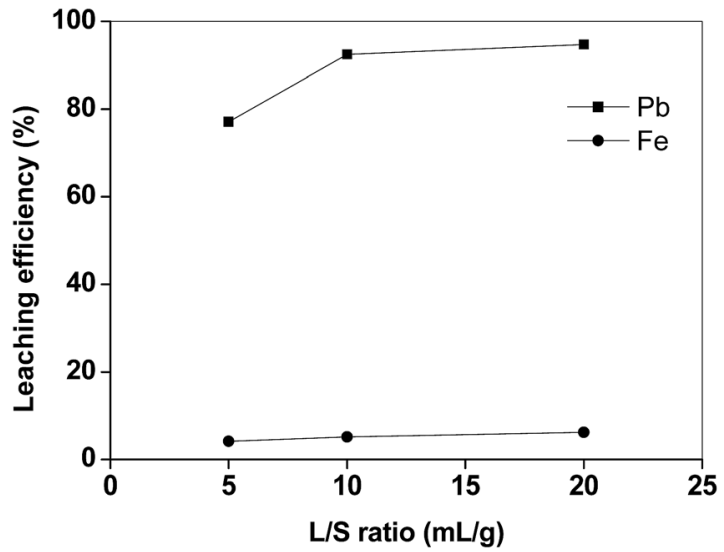

Fig. 4 Lead and iron leaching efficiency from the matte as a function of the liquid-to-solid ratio $\left(T=25^{\circ} \mathrm{C}, t=2 \mathrm{~h}\right.$ ).

$95 \%$ lead could be dissolved together with only $6 \%$ of iron. A higher selectivity for lead over iron could be obtained by selecting a lower liquid-to-solid ratio ( $\left.\mathrm{L} / \mathrm{S}=5 \mathrm{~mL} \mathrm{~g}^{-1}\right)$, but this resulted in a significantly lower lead leaching efficiency $(<80 \%)$. In this study $20 \mathrm{~mL} \mathrm{~g}^{-1}$ was selected as the optimal value from a technical point of view (maximum lead leaching efficiency). However, a liquid-to-solid ratio of $10 \mathrm{~mL} \mathrm{~g}^{-1}$ can be considered feasible as well in term of economy of the process.

The optimised set of parameters determined on the basis of the experiments described above is: time $(t)=2 \mathrm{~h}$; temperature $(T)=25^{\circ} \mathrm{C}$; liquid-to-solid ratio $(\mathrm{L} / \mathrm{S})=20 \mathrm{~mL} \mathrm{~g}^{-1}$. This set of parameters was used to determine the leaching efficiency and the concentration of the major and minor elements in the leachate (Table 3). The main elements in the leachate were found to be lead and iron, whilst nickel and zinc were present only at low concentrations. The concentrations of other elements (Cr, Mn, Sn,...) was below $1 \mathrm{ppm}$. The solid residue obtained after leaching the matte sample with the optimal operative conditions was separated from the leachate through vacuum filtration, washed with ultrapure water and dried in a vacuum oven at $50{ }^{\circ} \mathrm{C}$ until constant weight in order to determine the mass loss which was afterwards used to assess the mass balance. The mass loss was found to be about $15 \%$.

The lead could be recovered from the leachate by addition of sulphuric acid. The addition of sulphuric acid resulted in the precipitation of $\mathrm{PbSO}_{4}$, while the protons of the sulphuric acid regenerate the acetic acid. The precipitation tests were performed on a leachate obtained after leaching the matte in the

Table 3 Leaching efficiency and metal concentration in the leachate after leaching of the matte with acetic acid $\left(T=25^{\circ} \mathrm{C}, t=2 \mathrm{~h}, \mathrm{~L} / \mathrm{S}=\right.$ $20 \mathrm{~mL} \mathrm{~g}^{-1}$ ). This experiment was performed 6 times and the relative standard deviation (RSD) is given

\begin{tabular}{lllll}
\hline & $\mathrm{Pb}$ & $\mathrm{Fe}$ & $\mathrm{Ni}$ & $\mathrm{Zn}$ \\
\hline Leaching efficiency (\%) & 95 & 6 & 43 & 2 \\
Metal concentration (ppm) & 3706 & 1523 & 31 & 4 \\
RSD (\%) & 2.5 & 3.7 & 3.5 & 5.3
\end{tabular}




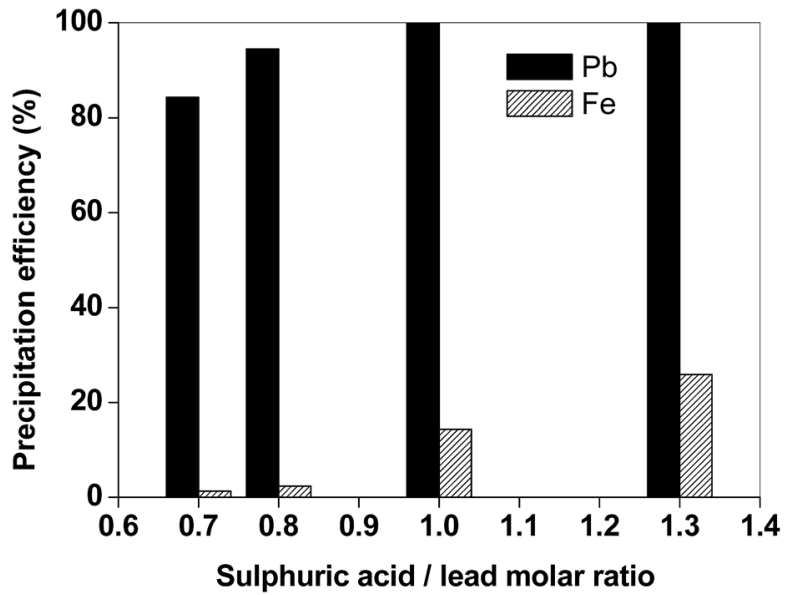

Fig. 5 Efficiency for precipitation of lead and iron from the matte leachate $\left(T=25^{\circ} \mathrm{C}, \mathrm{H}_{2} \mathrm{SO}_{4} 1 / 10 \mathrm{v} / \mathrm{v}\right)$.

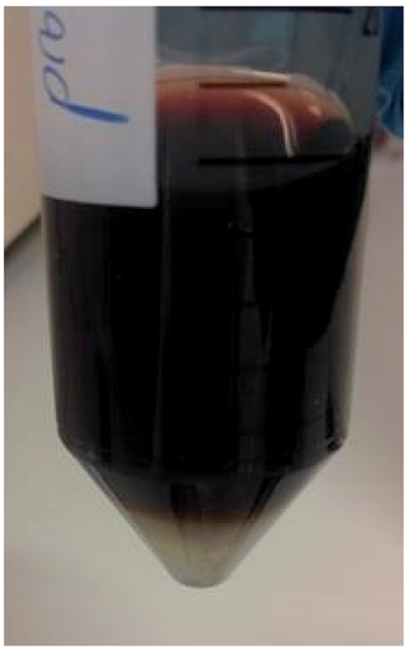

Fig. $6 \mathrm{PbSO}_{4}$ precipitate obtained by addition of $\mathrm{H}_{2} \mathrm{SO}_{4}$ to the acetic acid leachate of the matte.

optimal conditions with acetic acid $\left(T=25{ }^{\circ} \mathrm{C}, t=2 \mathrm{~h}, \mathrm{~L} / \mathrm{S}=\right.$ $\left.20 \mathrm{~mL} \mathrm{~g}^{-1}\right)$. The precipitation efficiency of $\mathrm{PbSO}_{4}$ was investigated as a function of the molar ratio (MR) of $\mathrm{H}_{2} \mathrm{SO}_{4}$ with respect to lead (Fig. 5). If a stoichiometric amount of $\mathrm{H}_{2} \mathrm{SO}_{4}$ is employed ( $\mathrm{MR}=1$, which corresponds to around 1 microliter of $\mathrm{H}_{2} \mathrm{SO}_{4} 1 / 10 \mathrm{v} / \mathrm{v}$ per $\mathrm{mL}$ of leachate), lead is quantitatively precipitated with partial iron co-precipitation (14\%). The dosage of $\mathrm{H}_{2} \mathrm{SO}_{4}$ significantly affects the selectivity over iron: if a small excess of $\mathrm{H}_{2} \mathrm{SO}_{4}$ is used ( $\mathrm{MR}=1.3$ ), co-precipitation of iron exceeds $20 \%$. Lead(II)sulphate is obtained as white-colored solid product, as shown in Fig. 6 . The residue was washed with ultrapure water and dried in a vacuum oven at $50{ }^{\circ} \mathrm{C}$ until constant mass. It was found that the amount of $\mathrm{PbSO}_{4}$ which can be obtained from the suggested process is around $115 \mathrm{mg}$ per gram of matte.

The recovery process was performed on a larger scale to obtain a sufficient amount of solid residues for analysis purposes. A sample of $20 \mathrm{~g}$ of matte was contacted with $400 \mathrm{~mL}$
Table 4 Chemical composition of the residue obtained after leaching of matte with acetic acid (wt\%)

\begin{tabular}{lcll}
\hline Element & Concentration $(w t \%)$ & Element & Concentration (wt\%) \\
\hline $\mathrm{Fe}$ & 56.8 & $\mathrm{Mn}$ & 0.3 \\
$\mathrm{Si}$ & 2.7 & $\mathrm{Zn}$ & 0.3 \\
$\mathrm{Cu}$ & 1.2 & $\mathrm{Ni}$ & 0.2 \\
$\mathrm{~Pb}$ & 0.6 & $\mathrm{Cr}$ & 0.2
\end{tabular}

Table 5 Metal concentration ( $\mathrm{mg} \mathrm{L}^{-1}$ ) of the eluate ${ }^{a}$ (water-leaching tests performed on the residue)

\begin{tabular}{llll}
\hline Element & Concentration $\left(\mu \mathrm{g} \mathrm{L}^{-1}\right)$ & Element & Concentration $\left(\mu \mathrm{g} \mathrm{L}^{-1}\right)$ \\
\hline $\mathrm{Cl}$ & 4700 & $\mathrm{Cu}$ & 201 \\
$\mathrm{SO}_{4}$ & 163000 & $\mathrm{~Pb}$ & 3800 \\
$\mathrm{As}$ & 8.6 & $\mathrm{Ni}$ & 14900 \\
$\mathrm{Cd}$ & 14.4 & $\mathrm{Zn}$ & 2900 \\
$\mathrm{Cr}$ & $<2.0$ & &
\end{tabular}

${ }^{a}$ Physical-chemical characteristics: $\mathrm{pH}=4.7, T=28{ }^{\circ} \mathrm{C}, \sigma$ (electrical conductivity) $=0.4 \mathrm{mS} \mathrm{cm}^{-1}$.

Table 6 Criteria for granular waste acceptance in landfills (transposed from Council Decision annex 2003/33/EC $\left.{ }^{28}\right)$ - limit values $\left(\mathrm{mg} \mathrm{kg}^{-1}\right)$ for compliance leaching test using BS EN 12457 at L/S $10 \mathrm{~L} \mathrm{~kg}^{-1}$

\begin{tabular}{llll}
\hline & $\begin{array}{l}\text { Inert waste } \\
\text { landfill }\end{array}$ & $\begin{array}{l}\text { SNRAW }^{a} \text { and } \\
\text { non-hazardous waste } \\
\text { co-disposed with SNRHW }\end{array}$ & $\begin{array}{l}\text { Hazardous waste } \\
\text { landfill }\end{array}$ \\
\hline $\mathrm{As}$ & 0.5 & 2 & 25 \\
$\mathrm{Cd}$ & 0.04 & 1 & 5 \\
$\mathrm{Cr}$ & 0.5 & 10 & 70 \\
$\mathrm{Cu}$ & 2 & 50 & 100 \\
$\mathrm{Ni}$ & 0.4 & 10 & 40 \\
$\mathrm{~Pb}$ & 0.5 & 10 & 50 \\
$\mathrm{Zn}$ & 4 & 50 & 200 \\
$\mathrm{Cl}$ & 800 & 15000 & 25000 \\
$\mathrm{SO}_{4}$ & 1000 & 20000 & 50000
\end{tabular}

${ }^{a}$ SNRAW: stable non-reactive hazardous waste.

of acetic acid at $25^{\circ} \mathrm{C}$ for $2 \mathrm{~h}$ in a beaker, agitated by a magnetic stirring bar. The leachate was separated from the solid residue by centrifugation and then treated by $\mathrm{H}_{2} \mathrm{SO}_{4} 1 / 10 \mathrm{v} / \mathrm{v}(\mathrm{MR}=1$, $T=25{ }^{\circ} \mathrm{C}$ ) to precipitate lead as $\mathrm{PbSO}_{4}$. The recovered $\mathrm{PbSO}_{4}$ as well as the leaching residue were washed with ultrapure water and dried in a vacuum oven at $50{ }^{\circ} \mathrm{C}$. Both samples were analysed by EDXRF (leaching residue) or ICP-AES $\left(\mathrm{PbSO}_{4}\right)$. The chemical composition of the residue is reported in Table 4. The analysis confirmed the effectiveness of acetic acid as leaching agent, since the lead concentration in the residue was only $0.6 \%$. Water-leaching tests were performed on this residue to verify the non-leachability of toxic elements (Table 5). It was found that most of the concentration values comply with the acceptance criteria in landfills for stable non-reactive hazardous waste and non-hazardous waste (Table 6). ${ }^{28}$ The only exception 


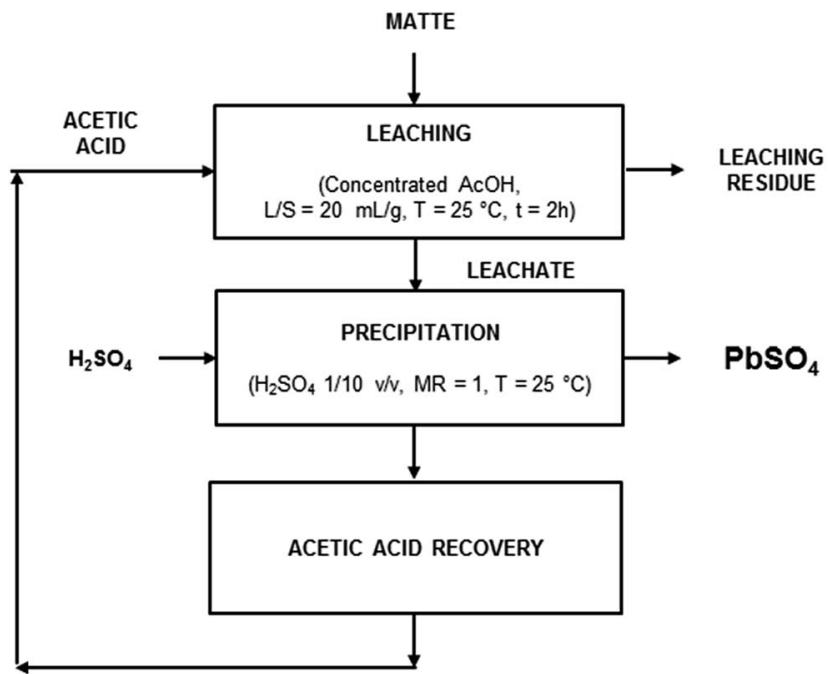

Fig. 7 Flow sheet for the closed-loop process to recover lead from matte by leaching with acetic acid $(\mathrm{AcOH})$.

is nickel, which has a concentration (15 ppm) higher than the regulatory limit $(10 \mathrm{ppm})$. Lead sulphate analyses by ICP-AES showed that the recovered product has a purity higher than $98 \%$. The $\mathrm{PbSO}_{4}$ can be used as secondary raw material for lead production.

In order to prove the feasibility of a closed-loop recovery process, the recovery of acetic acid was investigated as well. An aliquot of $20 \mathrm{~mL}$ of the leachate obtained by leaching of matte with acetic acid and precipitation of lead as $\mathrm{PbSO}_{4}$ using the optimised process parameters was evaporated under reduced pressure. The recovered acetic acid was employed for a new leaching step which, as expected, gave the same leaching efficiency for both lead and iron. Based on the experimental results, a recovery process flow-sheet is here proposed, which includes three main steps (Fig. 7): (1) leaching with concentrated acetic acid $\left(T=25{ }^{\circ} \mathrm{C}, t=2 \mathrm{~h}, \mathrm{~L} / \mathrm{S}=20 \mathrm{~mL} \mathrm{~g}^{-1}\right)$; (2) precipitation of $\mathrm{PbSO}_{4}$ with $\mathrm{H}_{2} \mathrm{SO}_{4} 1 / 10 \mathrm{v} / \mathrm{v}\left(T=25^{\circ} \mathrm{C}, \mathrm{MR}=1\right)$;

(3) recovery of acid by distillation.

In Table 7 the mass balance of the whole process is reported. It was assessed by using $1 \mathrm{~kg}$ of matte as functional unit. The lead concentration in the matte is drastically reduced (from $8.2 \%$ in the initial sample to less than $1 \%$ in the leaching residue), whilst the iron concentration is slightly higher $(\sim 57 \%)$ compared to the initial one (51.4\%), showing that there is an enrichment in iron content. This is an advantage for the use of the residue as a secondary iron source. The proposed solvometallurgical process requires only a small number of reagents, namely acetic acid and sulphuric acid. Only sulphuric

Table 7 Mass balance - matte

\begin{tabular}{lll}
\hline In & Matte & $1 \mathrm{~kg}$ \\
& Acetic acid & $20 \mathrm{~L}$ \\
& $\mathrm{H}_{2} \mathrm{SO}_{4} 1 / 10 \mathrm{v} / \mathrm{v}$ & $20 \mathrm{~mL}$ \\
Out & Residue leaching & $850 \mathrm{~g}([\mathrm{Fe}] \sim 57 \% ;[\mathrm{Pb}]=0.5-0.6 \%)$ \\
& $\mathrm{PbSO}_{4}$ & $115 \mathrm{~g}$
\end{tabular}

Table 8 Leaching efficiency and metal concentration in the leachate after leaching of the slag with acetic acid $\left(T=25^{\circ} \mathrm{C}, t=2 \mathrm{~h}, \mathrm{~L} / \mathrm{S}=\right.$ $20 \mathrm{~mL} \mathrm{~g}^{-1}$ )

\begin{tabular}{lrrrr}
\hline & $\mathrm{Pb}$ & $\mathrm{Fe}$ & $\mathrm{Sn}$ & $\mathrm{Zn}$ \\
\hline Leaching efficiency (\%) & 72 & 3 & 3 & 1 \\
Metal concentration (ppm) & 1370 & 548 & 2 & 2 \\
\hline
\end{tabular}

acid is consumed. Acetic acid can be recovered by distillation and re-used in the leaching step, thus reducing the volume of waste streams to be disposed of. During the distillation step, a residue was produced, but this was not studied further in this work. This can be attributed to the iron fraction dissolved during the leaching step and which is not precipitated in the separation step with sulphuric acid (around $27 \mathrm{~g}$ of iron per $\mathrm{kg}$ of matte). The leaching step is performed at room temperature, so the energy consumption is low. As mentioned above, the purity of the lead(II)sulphate is sufficient for use as a direct feed into a secondary lead smelter.

The optimal conditions determined for the treatment of the matte sample (concentrated acetic acid, $t=2 \mathrm{~h}, T=25^{\circ} \mathrm{C}, \mathrm{L} / \mathrm{S}=$ $20 \mathrm{~mL} \mathrm{~g}^{-1}$ ) were applied for the leaching of the slag sample. The results are shown in Table 8. A lower leaching efficiency for lead was obtained. This can be explained by the differences in mineralogical composition between the two samples: in the matte, lead is mainly present as metallic lead, which is soluble in weak organic acids,${ }^{14}$ whereas in the slag sample, lead is also present as sulphide $(\mathrm{PbS})$, which requires oxidising conditions for leaching. ${ }^{16}$

As in the case of the matte sample, the main elements in the leachate of the slag were found to be lead and iron. The separation of lead from iron was thus the objective of the next step. In Fig. 8, the efficiency for precipitation of lead and iron is reported as a function of the molar ratio. The experimental data showed that precipitation with $\mathrm{H}_{2} \mathrm{SO}_{4}$ is selective towards lead: if a stoichiometric amount of $\mathrm{H}_{2} \mathrm{SO}_{4}$ is added, quantitative precipitation of lead was observed with only limited iron coprecipitation $(10 \%)$.

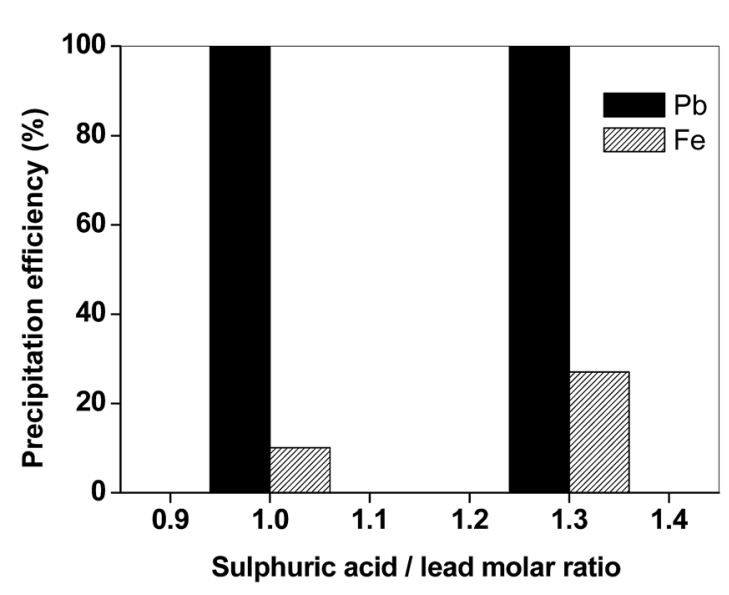

Fig. 8 Efficiency for precipitation of lead and iron from the slag leachate $\left(T=25^{\circ} \mathrm{C}, \mathrm{H}_{2} \mathrm{SO}_{4} \mathrm{1} / 10 \mathrm{v} / \mathrm{v}\right)$. 


\section{Conclusions}

Lead can be efficiently recovered from iron-rich residues from a secondary lead smelter process for recycling of lead from leadacid batteries (matte and slag) by a solvometallurgical process. The process is based on dissolution of lead by concentrated acetic acid, followed by precipitation of the dissolved lead as $\mathrm{PbSO}_{4}$ by addition of $\mathrm{H}_{2} \mathrm{SO}_{4}$. More than $90 \%$ of the lead present in the matte sample could be dissolved at room temperature, in a relatively short time ( 2 hours). The process is selective for lead, with codissolution of only small amounts of iron. Relatively pure $\mathrm{PbSO}_{4}$ could be obtained, with partial co-precipitation of iron, and this $\mathrm{PbSO}_{4}$ can be used as feed for a secondary lead smelter. Acetic acid could be recovered by distillation and reused in a second leaching step, showing the feasibility of a closed-loop process. The process was optimised for the recovery of lead from matte, in which lead is present in the metallic state. The solvometallurgical process was also applied to the slag, in which lead is present as PbS and metallic lead. Lead could be recovered from the slag by acetic acid leaching, but only the lead that was present in metallic state. Main advantages of this solvometallurgical process are the low power consumption (roomtemperature process), the low consumption of chemicals (only sulphuric acid), full recycling of the acetic acid and the limitation of aqueous waste stream generation.

\section{Conflicts of interest}

There are no conflicts of interest to declare.

\section{Acknowledgements}

The authors would like to thank the IWT Flanders for financial support (MIP ICON MaxiVia project, 2015-2017). This project was carried out with the support of the Flemish Region - Environmental and Energy Technology Innovation Platform (MIP).

\section{References}

1 H. Shen and E. Forssberg, Waste Manag., 2003, 23, 933-949. 2 M. Reuter, Y. Xiao and U. Boin, in VII International Conference on Molten Slags Fluxes and Salts, The South African Institute of Mining and Metallurgy, Johannesburg, 2004, vol. 20, pp. 349-356.

3 B. Das, B. Kanta Mishra, S. Angadi, S. Kumar Pradhan, S. Prakash and J. Mohanty, Waste Manag. Res., 2010, 28, 561567.

4 E. Rudnik, L. Burzyńska and W. Gumowska, Miner. Eng., 2009, 22, 88-95.

5 Z. Yang, M. Rui-Lin, N. Wang-Dong and W. Hui, Hydrometallurgy, 2010, 103, 25-29.
6 A. Lassin, P. Piantone, A. Burnol, F. Bodénan, L. Chateau, C. Lerouge, C. Crouzet, D. Guyonnet and L. Bailly, J. Hazard. Mater., 2007, 139, 430-437.

7 A. Smaniotto, A. Antunes, I. do N. Filho, L. D. Venquiaruto, D. de Oliveira, A. Mossi, M. Di Luccio, H. Treichel and R. Dallago, J. Hazard. Mater., 2009, 172, 1677-1680.

8 G. De Angelis, F. Medici, M. R. Montereali and L. Pietrelli, Waste Manag., 2002, 22, 925-930.

9 M. Penpolcharoen, Cem. Concr. Res., 2005, 35, 1050-1055.

10 M. Shirinbayan, H. Razavizadeh and M. R. Aboutalebi, Russ. J. Non-Ferr. Met., 2014, 55, 538-541.

11 L. C. Ferracin, A. E. Chácon-Sanhueza, R. A. Davoglio, L. O. Rocha, D. J. Caffeu, A. R. Fontanetti, R. C. Rocha-Filho, S. R. Biaggio and N. Bocchi, Hydrometallurgy, 2002, 65, 137-144.

12 E. Kim, L. Horckmans, J. Spooren, K. C. Vrancken, M. Quaghebeur and K. Broos, Hydrometallurgy, 2017, 169, 372-381.

13 E. Kim, L. Horckmans, J. Spooren, K. Broos, K. C. Vrancken and M. Quaghebeur, Hydrometallurgy, 2017, 169, 290-296.

14 C. A. Sutherland, E. F. Milner, R. C. Kerby, H. Teindl, A. Melin and H. M. Bolt, in Ullmann's Encycl. Industrial Chem., Wiley-VCH, Weinheim, 2005, vol. 20, pp. 551-597.

15 S. Aydoğan, A. Aras, G. Uçar and M. Erdemoğlu, Hydrometallurgy, 2007, 89, 189-195.

16 S. Nagib and K. Inoue, Hydrometallurgy, 2000, 56, 269-292.

17 E. C. Barrett, E. H. Nenniger and J. Dziewinski, Hydrometallurgy, 1992, 30, 59-68.

18 K. Binnemans and P. T. Jones, J. Sust. Metall., 2017, 3, 570-600. 19 D. Dupont and K. Binnemans, Green Chem., 2015, 17, 856-868. 20 G. R. T. Jenkin, A. Z. M. Al-Bassam, R. C. Harris, A. P. Abbott, D. J. Smith, D. A. Holwell, R. J. Chapman and C. J. Stanley, Miner. Eng., 2016, 87, 18-24.

21 A. P. Abbott, A. Al-Bassam, A. Goddard, R. C. Harris, G. Jenkin, F. Nisbett and M. Wieland, Green Chem., 2017, 19, 2225-2233.

22 R. K. Henderson, C. Jimenez-Gonzalez, D. J. C. Constable and A. D. Curzons, Green Chem., 2011, 13, 854-862.

23 R. K. Henderson, A. P. Hill, A. M. Redman and H. F. Sneddon, Green Chem., 2015, 17, 945-949.

24 C. M. Alder, J. D. Hayler, R. K. Henderson, A. M. Redman, L. Shukla, L. E. Shuster and H. Sneddon, Green Chem., 2016, 18, 3879-3890.

25 S. Riaño, M. Regadío, K. Binnemans and T. Vander Hoogerstraete, Spectrochim. Acta, Part B, 2016, 124, 109-115.

26 M. Regadío, S. Riaño, K. Binnemans and T. Vander Hoogerstraete, Anal. Chem., 2017, 89(8), 4595-4603.

27 J. S. Casas and J. Sordo, Lead: Chemistry, Analytical Aspects, Environmental Impact and Health Effects, Elsevier, 2011, pp. 26-27.

28 Environmental Agency, Waste Sampling and Testing for Disposal to Landfill, Environment Agency Horizon house, Bristol, 2013. 